Sultan Qaboos University Journal of Arts \& Social Sciences

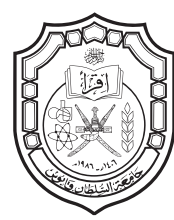

جامعة السلطان قابوس الإدمان مجلة الآداب والعلوم الاجتمأعية

\title{
Alerters in Sudanese Arabic and English Requests
}

\author{
Khalid Tag-Eldin \\ University of Bahri, Sudan \\ College of Business Administration \\ in Afif, Shaqra University, K.S.A. \\ khalidmogadam@su.edu.sa
}




\title{
Alerters in Sudanese Arabic and English Requests
}

\author{
Khalid Tag-Eldin
}

\section{Abstract:}

This study aimed at investigating the alerters produced by 200 Sudanese university students in their written response to two Arabic and English Discourse Completion Tasks. The study attempted to classify the different types of alerters collected using the two tasks based on their nature. Then, it compared and contrasted the precursors used by the subjects in the two languages. The study also examined the different functions of alerters produced by the participants. Moreover, it explored the impact of social distance, power relation, and degree of request imposition on the participants' choice of precursors. The study showed that Arabic utilizes precursors more often and with wider variety than English. Arabic displayed a total of sixteen types of alerters while English used eleven only. It was also found that the precursors were used to perform a variety of religious, social, and pragmatic functions. Moreover, it showed that different contextual factors influenced the subjects' choice of alerters.

Keywords: pragmatics; speech acts; alerters; English language; Sudanese Colloquial Arabic.

\section{الإنجليزيات الحديثة: واقع أم مثالية فكرية}

\author{
خالد تاج الدين
}

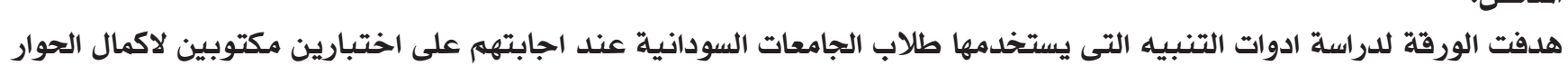

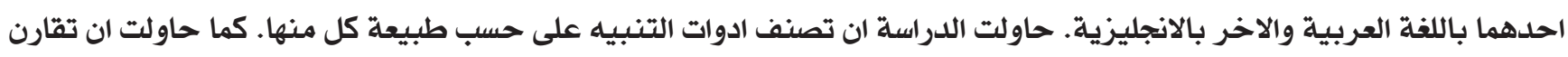

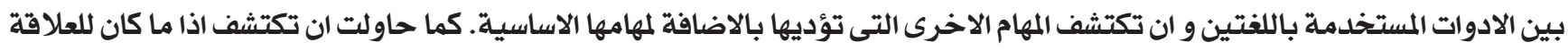

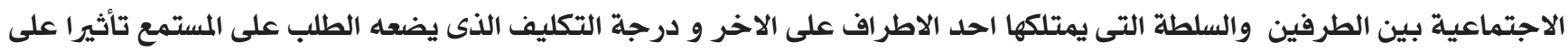
اختيار افراد العينة لادوات التنبييه. وجلت الدراسة ان اللغة العربية تستخدم ادوات تنبيه اكثر عددا وتنوعا من اللغة الانجليزية حيث تستيلة تستخدم ستة عشر نوعا بينما

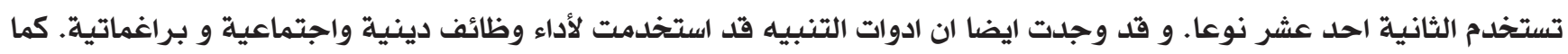

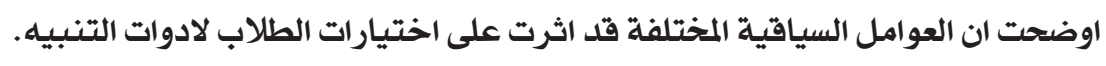
الكلمات المفتاحية: افعال لغوية، ادوات التنبيه، اللغة الانجليزية، اللغة العامية السودانية، طلاب الجامعات السودانية. 


\section{Introduction:}

Requests are considered one of the most important speech acts due to the role they play in different social interactions. They are performed to get information, seek others' cooperation, etc. The speech act is learnt earlier in life to facilitate smooth cooperation with members of one's social group. It is also acquired early in the process of learning a second or a foreign language.

A request is a pre-event speech act that is made to change the behavior of a person by making him/her perform an act that is desired by a speaker that is not planned to be carried out by the listener in the normal course of action. There are many types of requests such as requests for action, information, attention, sympathy, etc. (Sifianou, 1999). The speech act belongs to the class of directives (Searle, 1969). By its nature, a request threatens the faces of both the speaker and listener (Brown \& Levinson, 1987). Denial of performing the desired request by a requestee may result in embarrassment for the requester. A request threatens the face of the hearer as it puts imposition on his/her freedom of action. Therefore, performing a request requires employing different modifiers and politeness devices to soften its illocutionary force.

Structurally, a request could be divided into a head act and peripheral elements to the head act. The peripheral elements are divided into internal and external modifications. The different types of modifiers are used to mitigate or aggravate the degree of imposition of a request. The alerters are important part of external modifiers. They occur at the initial position of a request set and are used to draw the attention of the requestee to the oncoming request and to open communication channels.

Although there is ample literature about the speech act of requesting, the study of the area of modifiers has not been addressed adequately. There is a dearth of materials that cover the area of modifiers in general and alerters in particular within the domain of pragmatics.

The present study aimed at investigating alerters that occurred in request sets produced by Sudanese university students. The study tried to classify the different types of alerters used by the subjects in their responses to Arabic and English Written Discourse Completion Tasks (WDCT). It attempted to compare and contrast the subjects' production of the different modifiers in the two languages. It tried also to identify the reasons behind subjects' preferences of different types and the impact of social distance, power rela- tion, and degree of request imposition on the choice of precursors. It also aimed at describing other functions of alerters beyond their basic ones of drawing attention and opening communication channels.

\section{Classification of Alerters:}

Many studies that dealt with the speech act of requesting divided its structure into a head act, which is the minimal unit that carries its force and internal and external supportive moves that mitigate or aggravate it (Blum-Kulka et al., 1989; Blum-Kulka and Olshtain, 1984). The use of modifiers in request structures "serves to vary the politeness degree involved when performing this particular speech act, as well as to decrease or intensify the degree of imposition of the request" (Alcón et al. 2005: 4).

The alerter which is also known as a precursor, attention grabber (Nodoushan \& Allami, 2011), and presupport move (Culpeper \& Archer, 2008) is classified as an external supportive move. Precursors usually precede the head act or request proper and are used as introductory material to it. This element could be defined as a verbal device that is used to draw the hearers' attention to the requestive act that will follow. Blum-Kulka et al. (cited in Felix-Brasdefer, 2005: 73, and Achiba, 2003: 137) defined alerters as external elements that are used to draw the attention of the addressee to the "ensuing request". It also serves to ensure that the communication channel is open between interactants and that the requestee is ready to receive the request (Culpeper \& Archer, 2008). The device signals the "transition from a state of non-talk to a state of talk" (Lorenzo-Dus \& Bou-Franch, 2003). Eslamirasekh (1993: 91) noted that alerters were used as downgraders to soften the force of a request (e.g. dear) or as upgraders to intensify it (e.g. you fool). However, Culpeper and Archer (ibid: 73) contradicted her when they stated that alerters "can hardly be described as modifying the requestive force, [they] merely ensure that the channel is open".

Some examples of frequently used alerters presented by Blum-Kulka et al. (1989: 277) include names, surnames, nicknames, title roles, endearment terms, offensive terms, pronouns, attention getters, and combinations. Recent research did not agree on a unified or a comprehensive classification for this pragmatic phenomenon. For instance, Sifianou (1999) classified precursors into three categories which are formulaic entreaties, formulaic greetings and imperative constructions. Also, Marquez Riter (2002:142), in her study of the external modifications of requests in Span- 
ish, listed five types of alerters that include: discourse markers, apologetic formulas, first names, nicknames or titles, and greetings. While Nodoushan and Allami (2011: 84) found only five precursors in their study of the supportive moves of Persian requests. Those five were titles, greetings, names, discourse markers, and apologetic formulas. Moreover, Lorenzo-Dus and Bou-Franch (ibid) listed the following types in their study: (in)formal attention getters, greetings, names and nicknames, terms of endearment, and apologies. Table 1 provides different categories of alerters used by previous studies.

\section{Methodology:}

A total of 200 male and female Sudanese university students in their final year of study participated in this study. They were chosen randomly from eight national universities using a simple random sampling method. The sample was chosen from university students on the assumption that their educational backgrounds were similar, and that their familiarity with the contexts presented in the WDCTs will result in comparable responses. The subjects shared the same mother tongue; they spoke the Arabic dialect spoken in the capital Khartoum and other central states which is referred to as Sudanese Colloquial Arabic (SCA). They studied English as a foreign language for four years in basic education, three years at the secondary level, and two years at the tertiary level. The subjects were introduced throughout their study to the different types of English speech acts. Based on their previous study, they were supposed to be able to produce and understand requests in English.

The study used two versions of a Written Discourse Completion Task (WDCT). This elicitation technique is also known as the Discourse Completion Test (DCT), Discourse Completion Task (DCT), Discourse Completion Questionnaire (DCQ), and Dialogue Construction Questionnaire (DCQ).

The DCT is a widely used data collection instrument within the field of pragmatic research to gather different speech acts data. It is an elicitation questionnaire that consists of incomplete dialogues. Each dialogue is preceded by a contextual background of a particular situation that includes the relation between interactants involved. Respondents are asked to fill in a blank to complete the dialogue with a speech act that is appropriate to the provided situation (Burek, 2010).

The task has many advantages. Unlike other instruments, the DCT collects large amounts of data in a short period of time (Houck and Gass, 1996:46;
Table (1) Types of Alerters

\begin{tabular}{|c|l|}
\hline No & \multicolumn{2}{|c}{ Type } \\
\hline 1 & Apologies \\
\hline 2 & Greetings \\
\hline 3 & Entreaties \\
\hline 4 & Attention getters \\
\hline 5 & Names, Surnames, Nicknames, Titles \\
\hline 6 & Pronouns \\
\hline 7 & Discourse markers \\
\hline 8 & Endearment terms \\
\hline 9 & Offensive terms \\
\hline 10 & Imperative constructions \\
\hline
\end{tabular}

Kasper \& Roever, 2005:327; Beebe \& Cummings, 1996:80). It gathers comparable data from speakers of one or more languages (Houck \& Gass, 1996). Beebe and Cummings (ibid: 75) claimed that in many ways it "reflect[s] the content expressed in natural speech". Parent (2002: 150) noted that: "Other advantages of the method are controlling the contextual variables important to the study, as well as effectively comparing the strategies used by NSs and learners of the same language," On the other hand, critics state that it fails to collect "prosodic and nonverbal features of oral interaction" and that it allows subjects more time to produce utterances (Cohen, 1996: 25). In spite of its weaknesses, the DCT continues to be used more than any other device within the field of pragmatics. The WDCT items used in the present study contain scenarios that the subjects may see themselves in. All the situations are centered around the students' social and academic life. The situations are common and represent experiences that the subjects had already encountered or would likely to encounter during college years. The scenarios are intended to reflect subjects' lives and thus ensure the production of naturalistic data. Eslami-Rasekh et al. (2004: 5) emphasized the role of realistic situations in the production of naturalistic data. The Arabic version was written using the SCA spoken by all the subjects and it was used in test construction to ensure gathering spontaneous and realistic responses. Jianda (2006: 16) highlighted the importance of the use of real world language for test design. Each test contained a detailed description of nine situations. The subjects were asked to produce requests that were contextually and thematically suitable to each. The WDCTs were open ended so as not to put restraints on the length of speech acts produced. Table 2 describes the request desired to be 
Table (2) A description of the items of the English and Arabic WDCTs.

\begin{tabular}{|l|c|c|c|c|}
\hline \multicolumn{1}{|c|}{ Item } & Social Distance & Power Relation & Degree of Imposition \\
\hline 1-Ask head of department to write a recommendation letter. & Close & Hearer-dominant & Small \\
\hline 2- Ask a friend to allow subject to use his/her mobile phone. & Close & Status-equals & Large \\
\hline 3- Ask a cousin to bring a book. & Close & Speaker-dominant & Large \\
\hline 4- Ask a professor to raise his voice during lecture. & Distant & Hearer-dominant & Small \\
\hline 5- Ask a student in a dorm to turn down a music player. & Distant & Status-equals & Small \\
\hline 6- Ask a young girl to bring a blood test result in a clinic. & Distant & Speaker-dominant & Small \\
\hline 7- Ask a dean to move his/her car at a graduation ceremony. & Acquaintance & Hearer-dominant & Large \\
\hline 8- Borrow lecture notes from a colleague. & Acquaintance & Status-equals & Large \\
\hline 9- Ask a student to turn off a mobile phone during class. & Acquaintance & Speaker-dominant & Small \\
\hline
\end{tabular}

elicited by each item along with the social distance and power relation of subjects and other interactants as well as the degree of imposition of the requests. To improve the two tests, the researcher conducted a pilot study, and asked six Ph.D. holders to review them. The final drafts of the tests were answered by two groups, each one was comprised of 100 students. The first group responded to the Arabic version and the second to the English one. The researcher provided explanation to the subjects about how to respond to the tests without clarifying the nature of the speech act to be elicited by the two tasks. The subjects were given thirty minutes to complete the tests. The language errors in the collected data were out of the scope of this study.

Due to lack of a comprehensive or a unified classification of the pragmatic feature, the researcher designed a scheme that was based on the performance of the study subjects and previous studies (see Table 3 ) in which, precursors were categorized according to the nature of each type. The categories that were used to determine what an alerter is in the study's classification were:

(1) Position: alerters precede the head act as they occur in initial position.

(2) Function: a $\backslash$ alerters are used to draw the attention of the hearer; $b \backslash$ and to ensure that communication channel is open.

Although alerters occur with different speech acts, the present study focused exclusively on the alerters that are used with requests. Unlike when occurring with other speech acts, alerters are an important part of any request set and play a vital role in realizing the speech act.
Table (3) The classification of alerters used in the present study

\begin{tabular}{|c|l|c|}
\hline No & \multicolumn{1}{|c}{ Type } \\
\hline 1 & Apologies \\
\hline 2 & Greetings \\
\hline 3 & Professional Address Terms \\
\hline 4 & Deferential Address Terms \\
\hline 5 & Address Terms Stressing Gender \\
\hline 6 & Address Terms Stressing Close Social Relationship \\
\hline 7 & Endearment Address Terms \\
\hline 8 & Attention getters \\
\hline 9 & Names \\
\hline 10 & Pronouns \\
\hline 11 & Entreaties \\
\hline 12 & Small talk \\
\hline 13 & Diminutives \\
\hline 14 & Imperative Constructions \\
\hline 15 & The Calling Article yā \\
\hline 16 & Others \\
\hline
\end{tabular}

\section{Results and Discussion:}

The data gathered by the English and Arabic WDCTs showed that the subjects used a shared group of eleven alerters: apologies, greetings, professional address terms, deferential address terms, address terms stressing gender, address terms stressing close social relationship, endearment address terms, attention getters, names, pronouns, and entreaties. Those who responded to the Arabic test used five more precursors: small talk, diminutives, imperative constructions, the calling article yā , and other culture specific address terms.

The study also showed that the contextual factors of different situations determined the choice of precursors. The social distance, power relation, and degree 
of request imposition influenced the subjects' choice. Moreover, it was found that the choice of alerters was affected by the additional functions they serve. It was revealed that the different precursors used by the subjects were chosen to perform a religious duty, apologize for encroachment, show respect and deference, come socially closer to requestees, criticize misconduct, give advice and directions, summon hearers, and to express politeness.

As for the number of precursors used in the two languages, the results show that the Arabic subjects used significantly more alerters in the nine situations compared to those who responded to the English WDCT. The Arabic data contained 1450 precursors, while the English contained 679 . The difficulty in producing complex and detailed requests using the foreign language may be the reason behind the small number of the modifier which amounts only to $50 \%$ of the same feature in the students' production using their mother tongue. Table 4 shows the frequencies of use of the different types of alerters in the responses of the subjects to the two WDCT items.

The following is a detailed discussion of the results of the study covering the sixteen alerters used in the responses of the subjects:

\section{Apologies:}

With regard to the different types of alerters, the study showed that the English data used 89 instances of apologies, whereas the Arabic used six. The subjects used the apologetic formulas as precursors to prepare the hearers to the oncoming requests and as an external modification to the head act. When the students conceived that the hearer had more power than themselves or that the degree of imposition of the request was high they resorted to using apologies as alerters. For example, when the subjects were asked to issue a request to the dean of college to move his/her car as a response to situation number 7 they started with an apologetic formula. The following are examples taken from the subjects' data:

English data:

1-Sorry for the disturbance my teacher, please move your car.

2- We are sorry but it seems like your car is closing the entrance.

Arabic data:

3- ma'alish bas al-mawkib dair yidikhul min al-būabah ...

Sorry but the procession wants to enter through this gate...
Table (4) The frequencies of use of alerters in the students' responses to the English and Arabic WDCTs

\begin{tabular}{|c|c|c|c|}
\hline \multirow[b]{2}{*}{ No } & \multirow[b]{2}{*}{ Type } & $\begin{array}{l}\text { English } \\
\text { WDCT }\end{array}$ & $\begin{array}{l}\text { Arabic } \\
\text { WDCT }\end{array}$ \\
\hline & & \multicolumn{2}{|c|}{ Frequency } \\
\hline 1 & Apologies & 89 & 6 \\
\hline 2 & Greetings & 135 & 157 \\
\hline 3 & Professional Address Terms & 104 & 227 \\
\hline 4 & Deferential Address Terms & 63 & 10 \\
\hline 5 & Address Terms Stressing Gender & 25 & 88 \\
\hline 6 & $\begin{array}{l}\text { Address Terms Stressing Close Social } \\
\text { Relationship }\end{array}$ & 111 & 82 \\
\hline 7 & Endearment Address Terms & 41 & 66 \\
\hline 8 & Attention getters & 15 & 4 \\
\hline 9 & Names & 57 & 106 \\
\hline 10 & Pronouns & 27 & 6 \\
\hline 11 & Entreaties & 12 & 20 \\
\hline 12 & Small talk & 0 & 11 \\
\hline 13 & Diminutives & 0 & 20 \\
\hline 14 & Imperative Constructions & 0 & 78 \\
\hline 15 & The Calling Article yā & 0 & 557 \\
\hline 16 & Others & 0 & 12 \\
\hline & Total & 679 & 1450 \\
\hline
\end{tabular}

Also, when a subject needed to ask his professor to raise his/her voice as response to situation, number 4 he preferred to use an apology as a precursor:

4- m'alish yā ūstadh 'ala al-muqat'ah lakin niḥna ma qadrīn nasm' kiwais.

Sorry teacher for interrupting you, but we can't hear you well.

In another instance, a subject wanted to ask a roommate to turn down the volume of a music player as required by situation number 5 :

5-ma'alish yā shabāb ya'ni mumkin tawațu al- șawṭ shiwiah.

I am sorry guys, but can you turn down the volume?

The social distance and power relation of the interactants as well as the degree of imposition of the request influenced the subjects' choice of this type of precursors.

\section{Greetings:}

The subjects of the first group produced 135 English greetings, while the students in the other came up with 157 Arabic ones. In everyday communication, greetings are used as a social lubricant. Prophet Mu- 
hammed (PBUH) asked Muslims to exchange the Islamic greeting with each other to spread love, peace, and harmony among themselves. In accordance with the Prophet's teachings and as a religious obligation, Sudanese people exchange successive greetings at the beginning of every social contact. As a member of a collectivist society, a Sudanese believes that exchanging greeting expressions with other members displays the close social relation one has with them and thus increases the likelihood of their compliance with his/her request. Greetings reflect the interest of the speaker in the affairs of the requestee as they include inquiries about his/her life, work, health, family, etc. and they show that $\mathrm{s} /$ he is liked by the requester. The technique softens the encroachment of the request as it stresses the close social ties the speaker has with the hearer. The religious duty and the social functions of greetings may have influenced the subjects' choice of them as alerters. The following are examples taken from the subjects' responses to the two WDCTs:

English data:

6- Hi there good evening, how are you?

7- Hello, how are you Ms., I hope you are doing well. Arabic data:

8- asslamu 'alaikum, kaif akhbarak wa nas al-bait kaif 'amlaeen?

Peace be upon you. How are you and the family?

9-kaif tamam? wa khali wa nas al-bait kaif? kiwaisīn, keif ma'a alqeraiah?

How are you? How are my uncle and the family? Are they all right? How are you doing with your study?

\section{Professional Address Terms:}

The results showed that the English responses contained 104 professional address terms and the Arabic one had 227. For example, the subjects used professional address terms such as ūstadh that means "teacher", Prof., and diktur and dikturah that mean "a male and a female doctor" in their responses to the Arabic task and used the terms Prof., Doctor, etc. in their English responses. Such terms show respect on the part of the requester towards the requestee and thus increase the chances of his/her compliance with the request (Brown and Levinson, 1987). These types of alerters were used in the responses to situations number 1,4 , and 7 where the addressees enjoy a higher power status than the subjects.

An interesting finding was that professional address terms could be used sarcastically to criticize offenses. When some subjects needed to stop the offending conduct of addressees as responses to situations number 5 and 9 they resorted to addressing them by using the address term ūstadh. In the two situations the power relation between the two is that of equals and speaker dominant respectively. In the first, the offender was playing loud music and in the second $s /$ he was interrupting class with noisy ring tones. The Arabic data showed that several subjects used the professional address term to condemn the misconduct of the addressee and express their disappointment by hinting to the good behavior associated with the term that was expected from him/her. The strategy was preferred over others as the respect between interactants needs to be maintained due to their relation as a teacher and a student and as roommates.

\section{Deferential Address Terms:}

The study showed that the subjects who did the Arabic version used 10 deferential address terms and those who did the English task produced 63 terms. Deferential terms display that the speaker has a lower social or professional status than the addressee. The terms were used as a politeness strategy. Brown and Levinson (1987:178) explained that: "By conveying directly the perception of a high $P$ differential, deference serves to defuse potential face-threatening acts by indicating that the addressee's rights to relative immunity from imposition are recognized- and more than that $\mathrm{S}$ is certainly not in a position to coerce H's compliance in any way."

The Sudanese university students used deferential address terms such as al-saīd al-'amīd that means "Mr. Dean" and saīadtak which means "Sir/Your Excellency". The collected data showed that the high power the requestees have over the requesters had an impact on the choice of the precursors in situation number 7 .

Address Terms Stressing Gender and Social Relationships:

The English data included 25 address terms that stress the gender of the hearer, whereas the Arabic included 88 terms. The respondents used such terms in situations number 3 and 6 where they had power over the hearers. This type was used exclusively with junior members of the in-group. Sudanese avoid using it with adults due to its expected negative consequences. Many consider the use of such address terms with older people as a sign of hostility. The subjects employed it to come socially closer to the addressees by projecting the image of one of their senior family members and thus guarantee their compliance with 
the request.

The address terms that stress the social relationship between the two interactants appeared 111 times in the English data and 82 times in the Arabic responses. The subjects used address terms that create the illusion of having close social relations with other interactants. Respondents used a wide range of alerters to express the idea that the addressees are members of their in-group. The strategy was used to socially come closer to the requestee and thus increases the chances of his/her cooperation with the requester. The use of precursors as "social relation enhancers" is prevalent in Sudanese society. It is popular in Sudan to refer to strangers using terms that denote family ties to express warmth of relation and to guarantee their cooperation. It is common to address a stranger as father, uncle, grandfather, son, etc. Hassall (2001) assumed that using kinship terms of address is both positive and negative politeness strategy. The subjects used the attention grabbers intensively in their responses to situations where the power balance is in their favor or is equal to that of the others. They also used it scantly when they addressed others with high power. The following are instances of the terms taken from the responses to the two WDCTs:

English data:

10-Dear father, would you move your car from the main gate please?

11-Sister can you help me?

12-Hi daughter, I am sorry for disturbing you.

Arabic data:

13- yakhi ma tamshi tajīb li al-kitab.

Oh brother, why don't you go and bring me the book. 14- yā ibni mumkin taqfil talafunak.

My son can you turn off your phone?

\section{Endearment Address Terms:}

The subjects used endearment address terms 41 times in their English responses and 66 times in their Arabic answers. The choice of endearment terms as a precursor expresses the desire to establish a personal and close relation with the listener. It is a positive politeness strategy that implies the close and warm social ties the speaker has with the addressee and shows that $s /$ he is liked. The use of the device demonstrates interest in the hearer, the positive attitude of the requester, and expresses in-group solidarity. The alerter was used only with hearers of low power status. If it is used otherwise, then it will be considered as an indication of disrespect or flirting and thus endangers the chances of requestee's cooperation. The following are examples from the subjects' responses to the two tests:

English data:

15-little one, cute, beautiful girl, lovely Sarah, dear, honey, sweet, my love.

Arabic data:

16-ḥabibi, habibti "beloved one: addressed to a male first and then to a female"

17-'azizi , 'aziziti "dear: addressed to a male first and then to a female"

18-'asal

19- hilwah

20-'arūsah

21- sha țir, falih

"honey"

"cute girl"

"bride"

"clever"

Attention Getters, Names, Pronouns, and Entreaties:

The attention grabbers were used 15 times in the English WDCT and 4 times in the responses to the Arabic version. The precursor was used as response to situations number $3,5,6$, and 9 in which the speaker is dominant. The following are some examples:

English data:

22-hey

Arabic data:

23-hūy "hey you"

The English data contained 57 names and the Arabic 106. Using names when addressing others is another type of positive politeness. It shows respect for and interest in the listener. The subjects used imaginary names to address the requestees as alerters and politeness markers although the two tasks did not specify the name of any addressee in the nine situations.

As for the use of the pronouns as precursors, the subjects used them 27 times in the English task and 6 times in the Arabic one. The pronoun 'you' was used in the two WDCTs to draw the attention of the listener to stop an offense. The alerter was used in response to item number 9 where the requester's power is higher than that of the requestee and the offense needs a firm stance. The precursor was not used in other situations because it is considered as an indicator of disrespect, aggression, and hostility. The study subjects used also the indefinite pronouns as attention grabbers in situation number 9 when they played the role of a teacher in a summer school and wanted to ask a student to turn off a mobile phone. This type of pronoun was used to explain the regulations and give advice to all students. e.g.: 
English data:

24- anyone, everybody, everyone.

Arabic data:

25- kul wahid "everybody"

26- aiy wahid "anyone"

The subjects used the entreaties 20 times in the Arabic data and 12 in the English data. The strategy was used to indicate that the requestee enjoys a higher status than the speaker. The requester used entreaties to show deference and thus entice the hearer to comply with the request. The following is an example from the Arabic data:

27- ba'd idh nak yā prof yā rait bas t'ali șawtek shwia lanu ma samī'n

Excuse me Prof., we want you just to raise your voice a little because we can't hear you.

The results of the present study showed that in addition to the above-mentioned types of precursors, the Arabic language used five additional types. The following is a discussion of these types:

\section{Small Talk:}

The data gathered from the subjects of the study showed that they used "small talk" as a pre-support move. "Small talk" is defined as talking with the hearer about superficial topics that are not related to the goal of speech act to show that the speaker has an interest in the hearer and as an indicator of friendship (Brown \& Levinson, 1987:117; Beinstein, 1975) or to engage in a peripheral mode of talk (Coupland, 2000). The study subjects used the strategy 11 times. They asked questions about the requestee's name, family, health, and work. Asking such questions does not contribute to the realization of the speech act, as they do not address the requestive goal. The strategy was used to soften the imposition of the request because it shows the speaker's interest in and stresses the significance of his/her relation with the hearer.

The "small talk" was used by the subjects in their responses to the Arabic WDCT only. This could be attributed to the complexity of the linguistic structures needed to produce small talk in English and the limited linguistic resources available to them. It was used as response to situations number 3 and 6 where the speaker has power over the hearer. The following examples are taken from the subjects' Arabic data:

28- issmik minu?

What is your name? (addressed to a female)

29- nas al-bait kaif?

How is your family?
30- barak wala ma'ak ahalīk?

Are you alone or accompanied by your parents? (addressed to a female)

31- bithaḍri fi altelefizion?

Are you watching the T.V.? (addressed to a female)

Diminutive Address Terms:

When responding to the Arabic WDCT, the subjects used diminutive terms 20 times. This type of precursors was used only in the Arabic task, a phenomenon that did not exist in the English answers. The diminutive terms function as an expression of in-group membership (Brown \& Levinson, 1987: 108). Sudanese society is a kinship-based one that encourages the use of this strategy is used to display the close familial ties one has with the hearer. The use of the diminutives appeared in the subjects' responses to the Arabic task only. The same phenomenon was observed by Sifianou (1999) when she noted that the diminutives are not used very often in English. Their absence in the English data of the present study could be attributed to the subjects' unfamiliarity with the form in the foreign language. The subjects may have encountered difficulty in forming diminutives in English due to their lack of knowledge of the rules that govern the area. On the other hand, Arabic has a very rich grammatical system to generate them and they are intensively used in everyday interactions with others. This type of precursors was used as response to situations number 3 and 6 where the speaker has power over the requestee.

The following examples were found in the Arabic responses:

32-amūrah

33-sarūrah

"little princess"

34-binyah

"diminutive of the name Sarah"

35-wīlaid

"little girl"

"little boy"

\section{Imperative Constructions:}

The subjects used the two verbs isma" "listen" and ta'al "come" as precursors at the beginning of the request structures. The two imperative constructions were used by the subjects 78 times in their responses to the Arabic task. The two verbs were used as an introductory material to the upcoming requests. The openers were used only in situations number 3 and 6 where the addressees have less power than the subjects. The phenomenon is not manifested in other situations with different social power relations which indicate that their choice is determined by dominance relationship. The constructions were used to summon 
the addressee or to grab his/her attention.

\section{The Calling Article yā:}

The Arabic responses contained an intensive use of special article used to summon a hearer. This article is referred to as the calling article yā in Arabic grammar. Such as article or an equivalent to it is not found in the English data. The subjects used the device more than any other one; they used it 557 times in their answers. The article was used before names, address terms, etc. to specify the person to whom the request is addressed.

\section{Culture Specific Terms:}

The subjects used two culture specific address terms which are jama'ah "group of people" and zūwl "person". The two address terms were used 12 times in the subjects' responses. The two terms are culture specific as the former is used in Arabic language and SCA and the latter is an exclusive Sudanese address term that is used with both acquaintances and strangers. The terms were used to single out the person (s) addressed. The subjects avoided using these alerters with others who have more power.

\section{Conclusion:}

This study tried to examine the different types of alerters in the requests produced by Sudanese university students. It attempted to compare and contrast the different types of precursors in Arabic and English as well as to identify universal and culture specific ones. It also tried to identify the impact of social factors on the choice of precursors and the other functions they perform. The study subjects were 200 Sudanese university students. They responded to two WDCTs, one in Arabic and another in English. The two tasks contained the same nine situations.

The study revealed that the SCA utilized precursors more in number and variety than English as it used sixteen types and English used only eleven. The two languages used apologies, greetings, professional address terms, deferential address terms, address terms stressing gender, address terms expressing close social relations, endearment terms, attention getters, names, pronouns and entreaties. SCA, on the other hand, used an additional group that included small talk, diminutives, imperative constructions, calling article, and culture specific address terms.

The study showed that the social distance, power relation, and the degree of request imposition had an impact on the subjects' preference of the different types of alerters. It also found that precursors were used to perform other functions than drawing the attention of the hearer to the request as they were employed to carry out a religious act, apologize to soften a request, express deference, make and maintain social ties, criticize offense, explain rules, and show politeness.

The present study contradicted Blum-Kulka et al. (1989) and Culpeper and Archer's (2008) assumption that alerters have the mere function of drawing the attention of listeners to requests. It proved that they have social, religious, and pragmatic roles as well. It demonstrated that alerters affect the request by downgrading it as claimed by Eslamirasekh (1993) and is affected by the contextual factors that govern different situations.

Traditional language teaching curricula often focus on the different aspects of foreign languages, while they give little attention to the area of pragmatics. The rules of language use are of great importance. In the absence of such feature in language syllabi, even speakers with high levels of language competence are prone to commit pragmatic errors (Bardovi-Harlig, 1996). Teaching pragmatics is crucial as it helps learners become familiar with the different pragmatic devices and practices in the target language. The teaching of speech acts in general and requests and alerters in particular is vital to foreign learners, because they use them intensively in their interaction with others using English. The present study shed some light on the similarities and differences of alerters used in English and SCA, which may help learners to overcome transfer of the feature from their mother tongue and facilitate learning for them.

The study has restricted itself to the supportive moves that occur with requests. The study of alerters that are used with other speech acts may shed light on more types and functions. It focused on verbal precursors and did not touch on the area of non-verbal ones. Non-verbal alerters may be a rich area of research that needs to be addressed.

Future research may investigate:

1- Precursors preceding other speech acts

2- Alerters using other languages

3- Non-verbal gestures that serve as precursors

4- Politeness of different precursors

5- Alerters using other data collection instruments

6- Other contextual factors that determine the choice of the device 


\section{References:}

Achiba, Machiko. (2003). Learning to Request a Second Language: A study of Child Interlanguage Pragmatics. Clevendon: Multilingual Matters Ltd.

Alcón, E., Safont, P. and Martínez-Flor, A. (2005). Towards $A$ typology of modifiers for the speech act of requesting: A socio-pragmatic approach. RAEL: Revista Elctronica de Linguistica Aplicanda, 4, 1-35.

Bardovi-Harlig, Kathleen. (1996). Pragmatics and Language Teaching: Bringing Pragmatics and Pedagogy Together. In Lawrence F. Bouton. (Ed.) Pragmatics and Language Learning. (pp.21-39). Illinois: University of Illinois at Urbana-Champaign.

Beebe, Leslie M. and Cummings, Martha Clark. (1996). Natural speech act data versus written questionnaire data: How datacollection method affects speech act performance. In Susan M. Gass \& Joyce Neu (Eds.) Speech Acts Across Cultures: Challenges to Communication in a Second Language (pp. 65-86) Berlin; New York: Mouton de Gruyter.

Beinstein, Judith. (1975). Small Talk as Social Gesture. Journal of Communication, 25 (4), 147-154.

Blum-Kulka, Shoshana and Olshtain, Elite. (1984). Requests and Apologies: A Cross-Cultural Study of Speech Act Realization Patterns (CCSARP). Oxford: Applied Linguistics, 5(3), 196-213.

Blum-Kulka, S., House, J., and Kasper, G. (1989). Crosscultural Pragmatics: Requests and Apologies. Norwood, NJ: Alblex Publishing Corporation.

Brown, Penelope and Levinson, Stephen C. (1987). Politeness: Some Universals in Language Usage. Cambridge: Cambridge University Press.

Burek, Christina. (2010). Post-Merger Intercultural Communication in Multinational Companies: A Linguistic Analysis. Frankfurt am Main; New York: Peter Lang.

Cohen, Andrew. (1996). Investigating the production of speech act sets. In Susan M. Gass \& Joyce Neu (Eds.) Speech Acts Across Cultures: Challenges to Communication in a Second Language (pp. 21-44) Berlin; New York: Mouton de Gruyter.
Coupland, Justine. (2000). Introduction: Sociolinguistic Perspectives on Small Talk. In Justine Coupland (Ed.) Small Talk (pp. 1-26) England: Pearson Education Limited.

Culpeper, Jonathan and Archer, Dawn. (2008). Requests and directness in Early Modern English trial proceedings and play texts, 1640-1760. In Andreas H. Jucker \& Irma Taavitsainen (Eds.) Speech Acts in the History of English (pp. 45-84) Amsterdam; Philadelphia: John Benjamins Publishing Company.

Eslamirasekh, Zoherh. (1993). A Cross-Cultural Comparison of the Requestive Speech Act Realization Patterns in Persian and American English. Pragmatic and Language Learning Monograph Series, 4, 85-103.

Eslami-Rasekh, Zohreh., Eslamirasekh, Abbas., and Fatahi, Azizollah. (2004). The Effect of Explicit Metapragamtic Instruction on the Speech Act Awareness of Advanced EFL Students. Teaching English as Second or Foreign language, 8 (1), 1-22.

Felix-Brasdefer, J.Cesar. (2005). Indirectness and Politeness in Mexican requests, retrieved on 1 Feb. 2015 from http:// lingref.com/cpp/hls/7/paper1087.pdf.

Hassall, Tim. (2001). Modifying requests in a second language. IRAL International Review of Applied Linguistics in Language Teaching, 39 (4), 259-283.

Houck, Noel and Gass, Susan M. (1996). Non-native Refusals: A methodological Perspective. In Susan M. Gass \& Joyce Neu (Eds.) Speech Acts Across Cultures: Challenges to Communication in a Second Language (pp. 45-64) Berlin; New York: Mouton de Gruyter.

Jianda, Liu. (2006). Assessing EFL Learners' Interlanguage Pragmatic Knowledge: Implications for testers and teachers. Reflections on English Language Teaching, 5 (1), 1-22.

Kasper, Gabriele and Roever, Carsten. (2005). Pragmatics in Second Lnaguage Learning .In Eli Hinkel (Ed.) Handbook of Research in Second Language Teaching and Learning (pp. 317-334) Mahwah; New Jersey; London: Lawrence Erlbaum Associates, Publishers.

Lorenzo-Dus, Nuria and Bou-Franch, Patricia. (2003). Gender and Politeness: Spanish and British Undergraduate Perceptions of Appropriate Requests. In Jose 
Santaemilia (Ed.) Genero, Lenguaje y traduccion (pp. 183-199) Valencia: Universtat de Valencia.

Marqeuz Reiter, Rosina. (2002). Pragmatic variation in Spanish: External request modification in Uruguayan and Peninsular Spanish. Pragmatics, 12 (2), 135-151.

Nodoushan, Mohammad Ali Salmani and Allami, Hamid. (2011). Supportive discourse moves in Persian requests. International Journal of Language Studies (IJLS), 5 (2), 65-94.

Parent, Montserrat Perez. (2002). The production of Requests by Catalan Learners of English: Situational and Proficiency Level Effects. Atlantis, 24 (2), 147-168.

Searle, John. (1969). Speech Acts: An Essay in the Philosophy of Language. Cambridge: Cambridge University Press.

Sifianou, Maria. (1999). Politeness Phenomena in England and Greece: A cross-cultural perspective. Oxford: Oxford University Press. 